\title{
A Review of Smart Cities Based on the Internet of Things Concept
}

\author{
Saber Talari ${ }^{1}$, Miadreza Shafie-khah ${ }^{1,2, *}$, Pierluigi Siano ${ }^{2}$, Vincenzo Loia ${ }^{3}$, \\ Aurelio Tommasetti ${ }^{3}$ and João P. S. Catalão ${ }^{1,4,5}$ \\ 1 C-MAST, University of Beira Interior, R. Fonte do Lameiro, 6201-001 Covilhã, Portugal; \\ saber.talari@ubi.pt (S.T.); catalao@fe.up.pt or catalao@ubi.pt (J.P.S.C.) \\ 2 Department of Industrial Engineering, University of Salerno, 84084 Fisciano (SA), Italy; psiano@unisa.it \\ 3 Department of Management \& Innovation Systems, University of Salerno, 84084 Fisciano (SA), Italy; \\ loia@unisa.it (V.L.); tommasetti@unisa.it (A.T.) \\ 4 INESC TEC and Faculty of Engineering of the University of Porto, R. Dr. Roberto Frias, \\ 4200-465 Porto, Portugal \\ 5 INESC-ID, Instituto Superior Técnico, University of Lisbon, Av. Rovisco Pais, 1, 1049-001 Lisbon, Portugal \\ * Correspondence: miadreza@ubi.pt; Tel.: +351-275-242055
}

Academic Editor: Joseph H. M. Tah

Received: 8 January 2017; Accepted: 20 March 2017; Published: 23 March 2017

\begin{abstract}
With the expansion of smart meters, like the Advanced Metering Infrastructure (AMI), and the Internet of Things (IoT), each smart city is equipped with various kinds of electronic devices. Therefore, equipment and technologies enable us to be smarter and make various aspects of smart cities more accessible and applicable. The goal of the current paper is to provide an inclusive review on the concept of the smart city besides their different applications, benefits, and advantages. In addition, most of the possible IoT technologies are introduced, and their capabilities to merge into and apply to the different parts of smart cities are discussed. The potential application of smart cities with respect to technology development in the future provides another valuable discussion in this paper. Meanwhile, some practical experiences all across the world and the key barriers to its implementation are thoroughly expressed.
\end{abstract}

Keywords: cloud platform; Internet of Things (IoT); smart city; demand response

\section{Introduction}

\subsection{Concepts}

Because of the rapid rise of the population density inside urban environments, substructures and services have been needed to supply the requirements of the citizens. Accordingly, there has been a remarkable growth of digital devices, such as sensors, actuators, smartphones and smart appliances which drive to vast commercial objectives of the Internet of Things (IoT), because it is possible to interconnect all devices and create communications between them through the Internet [1]. In the past, it was difficult or even impossible to combine these digital devices. Likewise, gathering their information for day-to-day management of activities and long-term development planning in the city is essential. For example, some public transport information, e.g., real-time location and utilization, occupancy of parking spaces, traffic jams, and other data like weather conditions, air and noise pollution status, water contamination, energy consumption, etc. should be gathered continuously. To this end, different technologies have been applied to address the specific features of each application. The required technologies cover a wide range and layer from the physical level to the data and application layers. One of these technologies, proposed in [2], considered a two-way 
relay network with an orthogonal frequency division multiple accesses to achieve higher efficiency in smart grid communications.

The IoT archetype is in the power of smart and self-configuring devices which are well linked together by global grid infrastructures. IoT can be typically defined as a real object, largely dispersed, with low storage capabilities and processing capacities, while aiming at enhancing reliability, performance and security of the smart cities as well as their infrastructure [3]. On this basis, in the present paper, a survey of the IoT-based smart cities information from related reports is conducted.

The IoT consists of three layers, including the perception layer, the network layer, and the application layer, as shown in Figure 1. The perception layer includes a group of Internet-enabled devices that are able to perceive, detect objects, gather information, and exchange information with other devices through the Internet communication networks. Radio Frequency Identification Devices (RFID), cameras, sensors, Global Positioning Systems (GPS) are some examples of perception layer devices. Forwarding data from the perception layer to the application layer under the constraints of devices' capabilities, network limitation and the applications' constraints is the task of the network layer. IoT systems use a combination of short-range networks communication technologies such as Bluetooth and ZigBee which are used to carry the information from perception devices to a nearby gateway based on the capabilities of the communicating parties [4]. Internet technologies such as WiFi, 2G, 3G, 4G, and Power Line Communication (PLC) carry the information over long distances based on the application. Since applications aim to create smart homes, smart cities, power system monitoring, demand-side energy management, coordination of distributed power storage, and integration of renewable energy generators, the last layer which is the application layer, is where the information is received and processed. Accordingly, we are able to design better power distribution and management strategies [5].

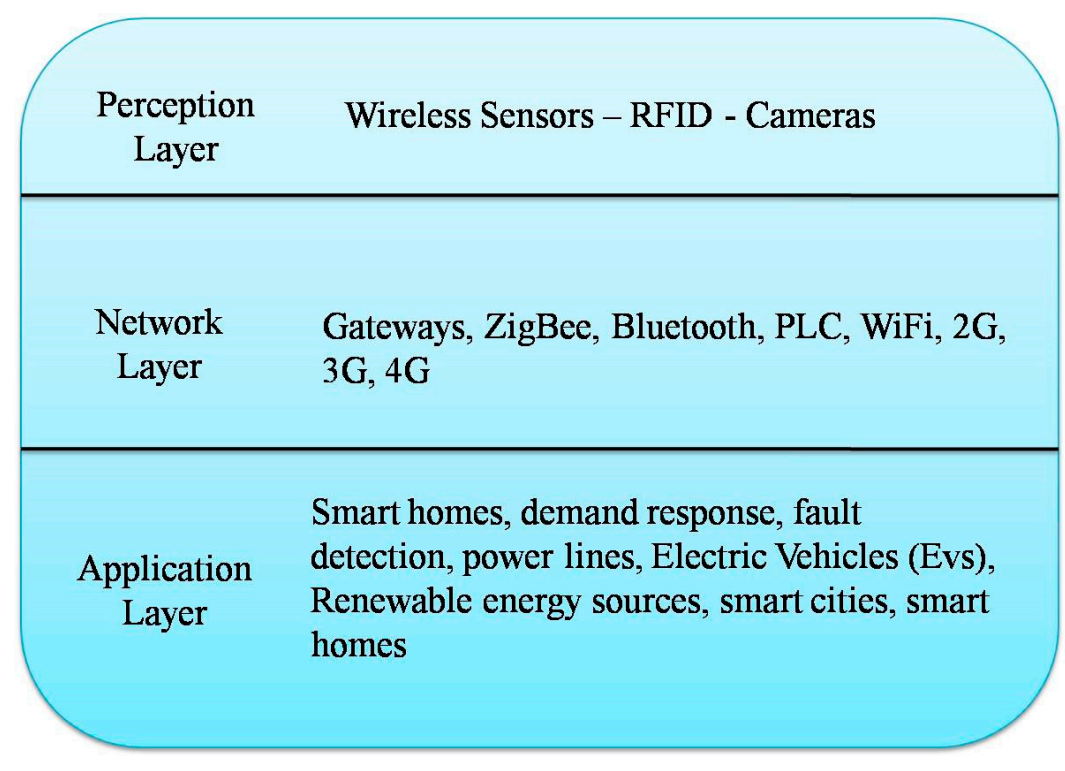

Figure 1. IoT layers.

\subsection{Motivations}

The smart city is becoming smarter than in the past as a result of the current expansion of digital technologies. Smart cities consist of various kinds of electronic equipment applied by some applications, such as cameras in a monitoring system, sensors in a transportation system, and so on. Furthermore, utilization of individual mobile equipment can be spread. Hence, with taking the heterogeneous environment into account, various terms, like characteristic of objects, participants, motivations and security policies would be studied [6]. Reference [7] presented some of the key features of potential smart cities in 2020. Smart citizens, smart energy, smart buildings, smart mobility, 
smart technology, smart healthcare, smart infrastructure, smart governance and education and finally smart security are the aspects of smart cities. The features of a smart city are shown in Figure 2.

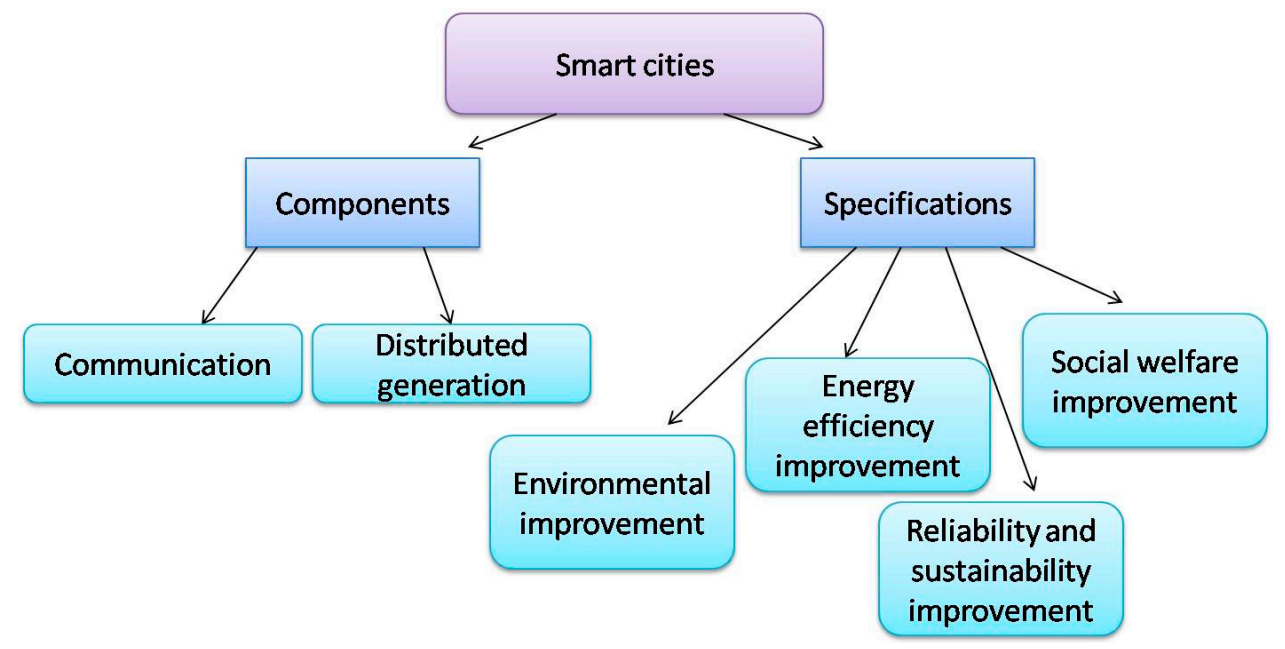

Figure 2. The key aspects of smart cities.

In an IoT environment, devices can be aggregated according to their geographical position and also assessed by applying analyzing systems. Sensor services for gathering specific data are utilized with some ongoing projects regarding the monitoring of each cyclist, vehicle, parking lot and so forth. There have been a lot of service domain applications which utilize an IoT substructure to simplify operations in air and noise pollution control, the movement of cars, as well as surveillance and supervision systems.

The developments on the Internet provide a substructure that enables a lot of persons to interlink with each other. The following development on the Internet may make it more applicable to arrange proper interlinks between objects. In 2011, the number of interconnected things was far higher than the amount of population [8]. Figure 3 shows the interconnection among the various objects based on the IoT [8]. Consequently, providing IoT improves cities and affects the different features of humans' life by creating cost-effective municipal services, enhancing public transformation, reducing traffic congestion, keeping citizens safe and healthier. Moreover, it plays a vital role in the national level associated with policy making (e.g., energy conservation and pollution reduction), monitoring systems, and needed infrastructures. Thus, it helps to supply a system with more efficiency, lower cost and more secure operation through energy conservation rules, economic attention as well as reliability level.

In personal and home applications, it can provide not only virtual entertainment but also real friendships. Controlling appliances like refrigerators and washing machines by IoT makes houses offer better energy management. Through the expansion of body area networks at home, it is possible to monitor the health situation of the elderly in their house, and this reduces treatment costs. Social networking applications like Facebook can collect the people of a city for an event or ceremony. It is helpful for making a connection with self-created communities either in texting, video or voice framework [8]. 


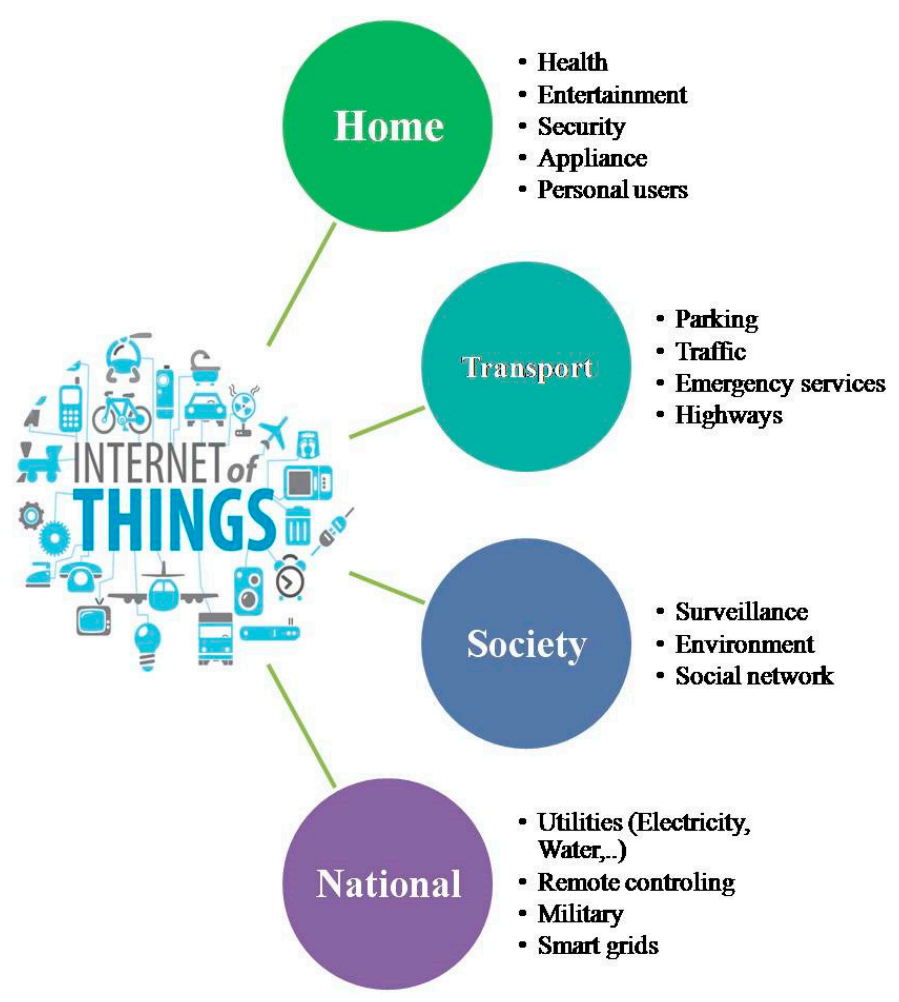

Figure 3. IoT-based linkages.

Since traffic congestion causes remarkable costs for a city from an environmental and citizen's time wasting perspective, smart transportation and logistics can help to mitigate the impact. Dynamic traffic information, online monitoring of travel times, route choice behavior can be conducted through the transport IoT and large scale WSNs. They also can develop stochastic models for mitigation plans and design algorithms for traffic control. Monitoring air and noise pollution by sensors within a IoT framework can help to take possible steps for reducing environmental concerns. Moreover, social services like providing better water quality and waste management can be obtained by monitoring water sources and water distribution systems.

\section{IoT Technologies for Smart Cities}

The IoT is a broadband network which employs standard communication protocols $[9,10]$, whereas the Internet would be its convergence point. The major notion of the IoT is the widespread existence of objects which are able to be measured and inferred, as well as it is able to modify the situation. Accordingly, IoT is empowered by the expansion of several things and communication equipment. Things in the IoT involve smart equipment such as mobile phones and other facilities including foodstuff, appliances and landmarks $[11,12]$ that can collaborate to achieve a joint objective. The main characteristic of the IoT is its effect on consumers' life [7]. In the concept of IoT, since the cabling cost for millions of sensors is expensive, the communication between sensors should be wireless. Low-power standard communication is suitable for interconnection among many devices. According to location and distance coverage, some networks are introduced as follows.

1. Home Area Networks (HAN) which use short-range standards like, ZigBee, Dash7, and Wi-Fi. All monitoring and control components in a home are connected by the HAN.

2. Wide Area Networks (WAN), provide communication between customers and distribution utilities which require much broader coverage than HAN and for implementation needs fiber cable or broadband wireless like $3 \mathrm{G}$ and LTE.

3. Field Area Networks, which are used for connection between customers and substations [5]. 
In IoT, two tasks, including sensing and processing the data, are performed, but they are not unified from a wireless sensor network (WSN) viewpoint. The unified solutions are Speakthing and iOBridge. Speakthing is an analytics IoT platform for gathering, visualizing and analyzing the live data in the cloud and you are able to analyze the data by MATLAB coding. In contrast, iOBridge has its own hardware modules that are connected to the cloud which can be accessed by web interfaces and collected data can be aggregated to other web services. It is noteworthy that cloud is very important in smart cities for data storage and processing. The IoT-related technology is explained in this section.

\subsection{Radio-Frequency Identification (RFID)}

RFID including readers and tags has a vital task in the framework of the IoT. Employing the technologies on each related thing, accomplishing their automatic identification and dedicating the single digital identity to any of the things will be possible, to include the network associated with the digital information and services [13]. RFID provides some applications in smart grids, including tracking and localization of objects, healthcare applications, parking lots and asset management. Each tag can be as a sensor because they have not only data which is written manually but also capture data like environmental information.

\subsection{Near Field Communication (NFC)}

Near Field Communication (NFC) is used for bidirectional short distance communication, especially in smart-phones. This range usually involves a centimeter range. The application of NFC in smartphones enables us to use it in smart cities, as well. One of its applications includes using smartphones with NFC as a wallet which enables us to use smartphones as our personal cards such as bank card, identification card, public transportation card, access control cards. Moreover, since NFC is bi-directional, it can be used to share data between devices, multimedia, and documents [5]. By placing NFC at a strategic position at the house and providing an interface with the central controller, it is possible to change the status of objects by checking the location for example switch on the Wi-Fi when the user comes home.

\subsection{Low Rate Wireless Personal Area Network (LWPAN)}

LWPAN is amongst short-range radio technology, that covers large distances of up to 10-15 km. The energy consumption of this technology is extremely low and battery lifetime is about 10 years [2]. According to the IEEE 802.15.4 standard, it provides low cost and low-rate communication for sensor networks. It has the lowest two layers of protocols including physical and medium access level, besides upper layers protocols including 6LoWPAN and ZigBee [14].

\subsubsection{ZigBee}

In the sensor nodes, ZigBee is applied as a low-power and low-cost wireless communication technology [5]. It is based on the IEEE 802.15.4 standard and is suitable for creating wireless personal area networks (WPAN) such as home automation, medical device collection and other low-power, low-bandwidth. Some of its applications include wireless light switches, electrical meters, and traffic management systems. ZigBee is suitable for limited ranges, coverage of city region and supporting billions of devices. With the ZigBee-based network, a mechanism for transmission of IPv6 packets is specified. To apply ZigBee, additional equipment usually is required involving a coordinator, router and ZigBee end-devices.

\subsubsection{LoWPAN}

The 6LoWPAN standard is specified to adapt IPv6 communication. Over the time, IPv4 which was the leading addressing technology supported by Internet hosts has been replaced by IPv6 due to the exhaustion of its address blocks and the inability to separately address billions of nodes which is a 
characteristic of IoT networks. IPv6 by providing 128-bit addresses solves the lack of enough nodes for IoT networks, but it creates another problem however, which is compatibility with constrained nodes. This problem is addressed by 6LoWPAN which is the compression format for IPv6 [15].

\subsection{Wireless Sensor Networks (WSNs)}

WSNs make diverse proper data available and might be applied in lots of uses like healthcare, as well as government and environmental services [12]. Moreover, WSNs can be aggregated with RFIDs to obtain several targets such as gaining data related to the position of people and objects, movement, temperatures, etc. A WSN consists of wireless sensor nodes which include a radio interface, an analog-to-digital converter (ADC), multiple sensors, memory and a power supply [5]. The different parts of a wireless sensor node are illustrated in Figure 4. According to the wireless sensor node framework, it includes various kinds of sensors which measure data in analog format which are converted to digital data through an ADC. Some procedures are processed on the data through a memory and microcontroller according to data requirements. Finally, data are transmitted by a radio interface. All of this equipment needs to be equipped with a power supply.

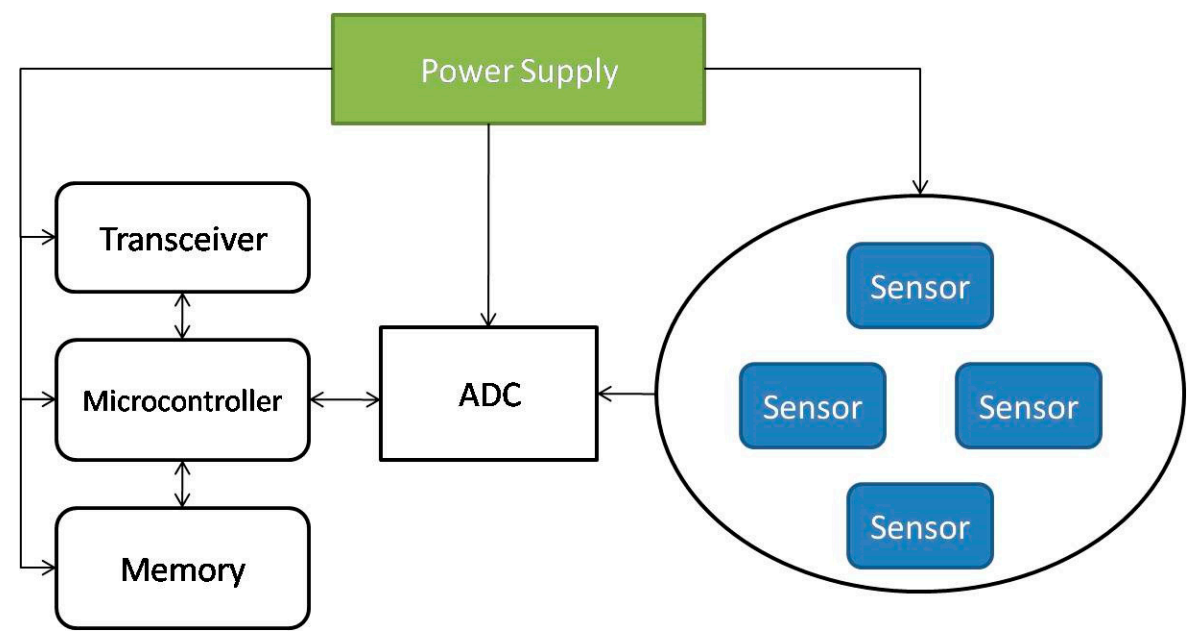

Figure 4. The architecture of a wireless sensor node.

A completed WSN is an extremely tiny low-power, low-cost sensor node which can be applied in any environment and works continuously for a few years. In reality, this utopic WSN has not been realized. WSN has severe source constraints like reliance on battery life. With a large number of sensor nodes in smart cities, replacing or recharging their batteries is infeasible. Designing a protocol for sophisticated power management schemes like solar panels is essential for WSN power sources.

\subsection{Dash7}

Dash 7 is a promising standard for WSNs used in long distance and low power sensing applications such as building automation and logistics. This protocol is for kilometer-distance range and operates at $433 \mathrm{MHz}$ which not only has better penetration through walls than $2.4 \mathrm{GHz}$ but is also appealing for HANs. It is worth noticing that Dash is very attractive in military application especially substation construction. Some of its applications are hazardous material monitoring, manufacturing and warehouse optimizations and smart meter development [16].

\section{6. $3 G$ and Long Term Evolution (LTE)}

3G and LTE are standards for wireless communication for mobile phones and data terminals. Regarding the development and expansion of wireless communication infrastructures, LTE and 3G are available everywhere, even in third world countries. This technology is for broadband connectivity and 
was not designed for short range uses. Hence, it is applied for WANs which require longer distance ranges. Nevertheless, there are some barriers to their implementation that should be addressed. High data cost due to providing this service by the service providers, and inability to use them for communication among billion devices are some of the problems of these services.

\subsection{Addressing}

The Internet empowers a significant interconnection among persons, and similarly, the current tendency in the IoT creates an interconnection of things and stuff, for providing smart environments [8]. For this purpose, the ability of exclusively identifying devices and things is essential for desirable results of the IoT. The reason behind this is the fact that exclusively addressing the large-scale mixture of things is crucial to control them through the Internet. Besides the expressed exclusivity idea, reliability, scalability and strength indicate the main needs to establish an improved unique addressing structure [8].

\subsection{Middleware}

Due to several concerns regarding the heterogeneity of contributing objects, to the limited storage and processability, along with to the huge different kinds of application, the middleware has a vital task in the interconnection of the things to the applications' layers. The main target of the middleware is to briefly aggregate the functionality and communication abilities of all included devices.

\subsection{Smart Cities Platforms and Standards}

The relationship between the physical and IT infrastructure constructs a novel machine-to-machine (M2M) communication for smart cities which along with new features of network drives smart cities' communication platforms. These platforms help to cover the communication requirements between heterogenous access technologies and application suppliers. Moreover, these platforms help form the IoT with real world sensors and communication networks. One of these platforms which is being used widely is openMTC extracted from the latest ETSI standards for the smartM2M specification. The aim of the openMTC platform is to provide a compliant middleware platform for M2M applications and implementation of the smart city [17].

As introduced earlier, the main standard for smart cities is IEEE 802.15 which is for wireless personal area networks. This standard consists of different parts including: 1-Bluetooth, 2-coexistence, 3-high rate WPAN, 4-low rate WPAN, 5-mesh networking, 6-body area networks, 7-visible light communication, 8-peer aware communication, 9-key management protocol, 10-layer 2 routing, 11—wireless next generation standing committee [18].

\section{Actual IoT Applications for Smart Cities}

The IoT uses the Internet to merge various heterogeneous things. Accordingly and for providing the ease of access, all existing things have to be linked to the Internet. The reason behind this is that smart cities include sensor networks and connection of intelligent appliances to the internet is essential to remotely monitor their treatment such as power usage monitoring to improve the electricity usage, light management, air conditioner management. To get this aim, sensors are able to be extended at various locations to gather and analyze data for utilization improvement [3]. Figure 5 illustrates the major utilizations of the IoT for a smart city. The key aims in this field of knowledge are expressed in the following subsections. 


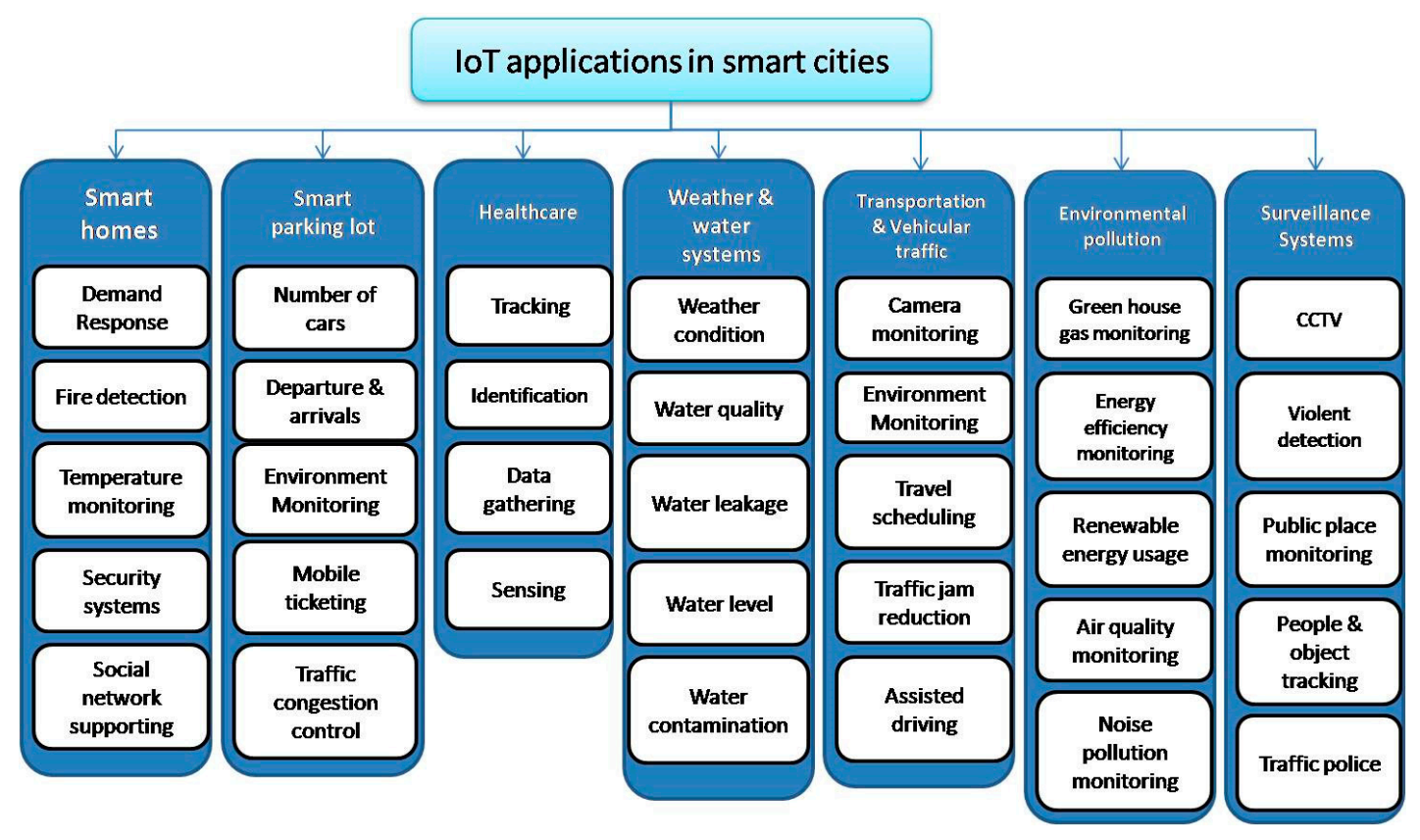

Figure 5. The main applications of the IoT.

\subsection{Smart Homes}

By utilizing the data which are produced by various sensors, smart homes can be observed [19]. For example, novel demand response (DR) methods can be applied, or customers can be cautioned in the case where pollution is above its acceptable limit through monitoring the pollution. In fact, IoT technology leads to having smart houses and appliances including smart TVs, home security system, lighting control, fire detection, and temperature monitoring. The sensors of this appliances monitor the conditions and environment and send surveillance data to a central controller at home which enables the householder to continuously monitor and control the home even from outside and make the best decision under every circumstance [20]. Likewise, these surveillance data aid to predict future events to be prepared in advance by taking an efficient measurement to prevent losing convenience, security, comfort and high standard of living. Moreover, smart houses in a neighborhood can be connected together through Neighbor Area Network (NAN) to form a smart community [21]. In this case, houses are able to share some surveillance data like outside camera to find an accident or report events to a police station. Healthcare, managing shared resources, and enabling support social networking are other applications of the smart communities. Hence, this concept is not only connection of neighbors but also extension and development of a comprehensive smart city which can monitor and control entire activities in a smart city [4].

\subsection{Smart Parking Lots}

By enabling smart parking, arriving and departing times of different cars are traced all over the city [22]. Thus, these parking lots have to be planned in such a way to take a number of vehicles in every region into account [23]. Furthermore, new parking lots have to be set up where there are more cars [24]. Accordingly, the data of smart parking lots are able to provide profits for both customers and merchants' daily lives in the smart cities. This service works based on road sensors and intelligent displays which lead drivers to the best path for parking in the city [25]. Some benefits of this service are finding a parking lot faster which means fewer $\mathrm{CO}$ emissions from the cars, lesser traffic congestion, and happier citizens. It can be integrated into urban IoT infrastructures. Moreover, by short-range communication technologies like RFID and NFC, it is possible to realize an electronic verification of parking permits and allows for offering better services to citizens [15]. 


\subsection{Healthcare}

In the healthcare domain, IoT technologies have many advantages in smart cities. Some of those applications are tracking of people and objects including patients, staff and ambulance, identification of people, and automatic data gathering and sensing. In terms of people and objective tracking, the status of patients in a clinic or hospital is monitored in order to provide better and faster work-flow in the hospital. The location of the ambulance, blood products and different organs for transplantation are monitored to check the availability on-line. In terms of people identification, in a database, patients are recognized to decrease the risk of mistake for prevention of getting wrong drugs, doses and procedures [26]. The staff authentication aims to improve the employee's behavior toward patients. Regarding the data collection and sensing, it helps to save time for data processing and preventing human errors. Through sensor devices, diagnosing patient conditions, providing real-time information on patient health indicators such as prescription compliance by the patient is implemented. By using bio-signal monitoring, the patient condition is investigated through heterogeneous wireless access-based methods to enable for getting the patient data anywhere [9].

\subsection{Water and Weather Systems}

Weather systems use diverse sensors to supply proper data such as temperature, rain, solar irradiation and wind speed, as well as to help enhance the efficiency of a smart city [3]. Besides the electricity one, water distribution systems are essential parts of every smart city. Conventional methods of water distribution from the water source to the customer premises are not suitable and efficient, especially for diagnosing any leakage in the pipeline or other parts of the system. Therefore, by deploying sensors at appropriate locations of the distribution system, it becomes an intelligent one for detection of any kind of faults or other applications. Water distribution systems have some parts including a water source like a lake or a river, storage facilities like reservoirs, and distribution networks like under- or aboveground pipelines which can be seen in Figure 6. Detection of faults like leakage, the quality of water and the level of reservoir water can be implemented through placing sensors in an IoT-based environment. Figure 6 demonstrates the location of sensors in different parts of water distribution systems. Accordingly, within a storage tank, the level of water is measured by placing an ultrasonic sensor on the top of the tank, and two pressure transducers at the bottom. The quality of water can be measured both after and before the storage tank at strategic locations by a glass electrode for measuring water $\mathrm{pH}$. The leakage can be detected in pipelines through three different sensors including vibration (using dual-axis accelerometers), pressure (piezo-resistive sensor) and sound (ultrasonic sensor) monitoring [5] which can be seen in the left part of Figure 6.

Aside from when a city experiences too much or too little rain, many of them face severe problems with water. According to the requirements of a region, local utilities can develop innovative methods to plan and manage irrigation, solving excessive water consumption, improvement of water conservation and allocating their scarce resources more effectively, addressing flooding and wastewater management during a storm through IoT. Dumping raw sewage into the local waterways will occur unavoidably in a region without any management and plan. IoT helps teach local authorities for management and plan everything regarding water such as controlling a huge amount of raw sewage and more effective preparation for storms. Cities through systems that monitor the weather and those that control the rainwater storage are able to gather data for determination of water supplies status. With a suitable method, cities will reduce the overflow of sewers and minimize the water contamination. Furthermore, using a system of sensors for gathering data on the water level of groundwater sources and rivers, it is possible to anticipate flood incidents. These system sensors are based on ultrasonic range finders and placed above local waterways to measure the changes in water level and predict the flood risks. IoT through TV whitespace channels which local telecom providers made it available, enables cities to make public awareness announcements about the flood in a real-time [27]. 


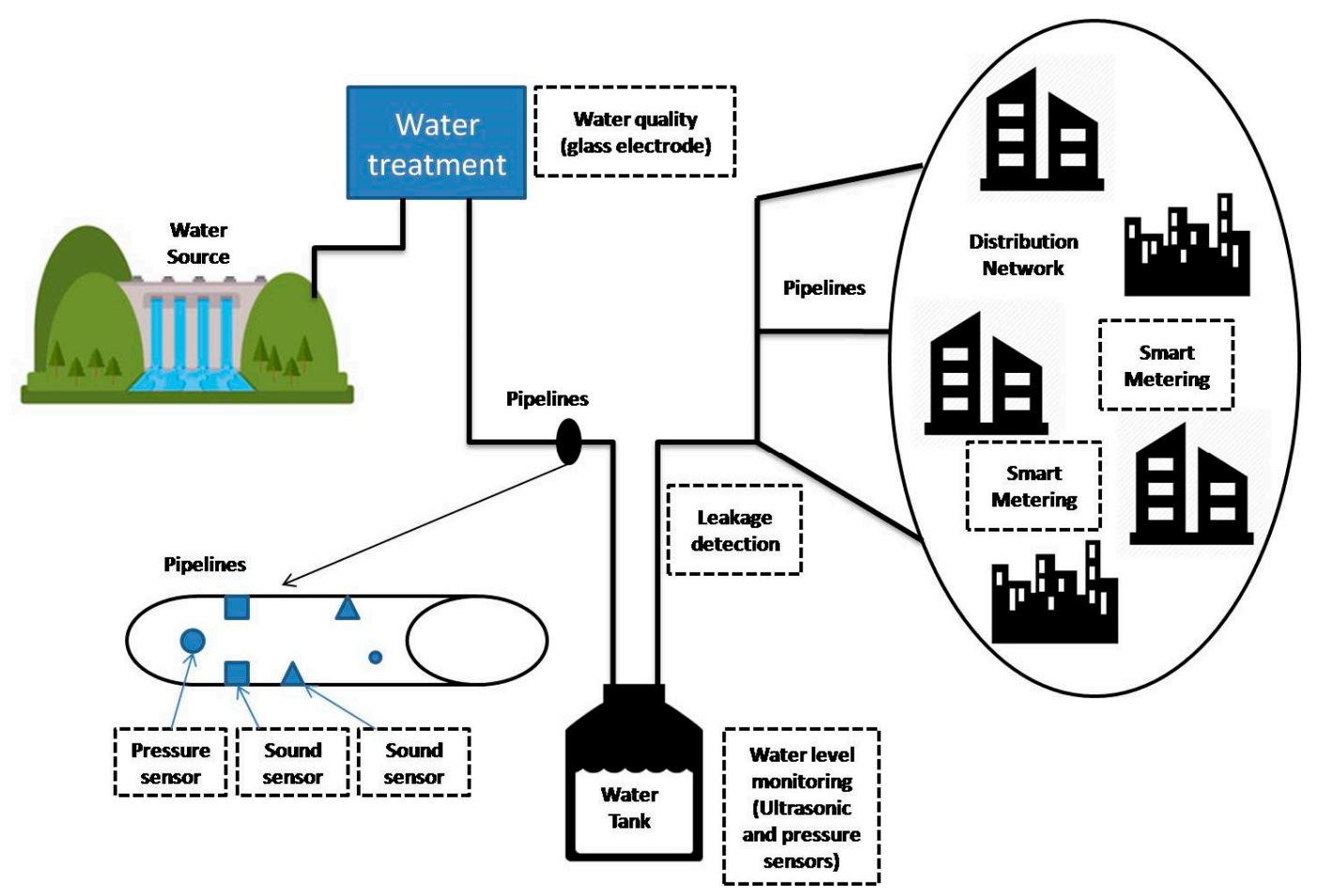

Figure 6. Smart water distribution.

\subsection{Transportation $\mathcal{E}$ Vehicular Traffic}

The vehicular traffic information is a substantial source of data in smart cities whereby utilizing the data and employing a proper analysis, residents and the government will profit significantly [22]. Residents can utilize the vehicular traffic information to define the arrival times at their destinations [28]. Monitoring the traffic congestion in the smart city by urban IoT should be implemented. However camera-based traffic monitoring systems are already available in many cities, they require more powerful communication infrastructure to provide more information. Traffic monitoring is conducted by sensing capabilities, GPS installed on modern vehicles and a mixture of air quality sensor and acoustic sensors along the given road [29]. This information is essential for authorities and citizens to discipline traffic and to send officers, as well as to plan the best way to reach the office or a shopping center [15].

\subsection{Environmental Pollution}

A city cannot be considered as smart if the residents are not healthy. For this purpose, environmental pollution has to be monitored by the smart city and the relevant data sent to residents, particularly to people with healthcare problems. Reference [1] also accounted for independent modules to obtain noise and other environmental information. There is a plan in the European Union for the reduction climate change using renewable energy sources. The target is $20 \%$ reduction in greenhouse gas emissions by 2020 compared with 1990 and a $20 \%$ cut in energy consumption through improvement of the energy efficiency, and a $20 \%$ increase in renewable energy usage. To this end, an urban IoT can be applied to monitor the quality of air through using outdoor sensors in locations like rivers or parks. Moreover, communication facilities can be provided to assess the quality of air, quality of water and other parameters such as humidity, temperature, ambient carbon dioxide level and other harmful gases and ensure pollution is at an acceptable level [15]. Noise can be considered as an acoustic pollution. Authorities should implement laws to reduce noise pollution in city centers at specific hours. An urban IoT can monitor the amount of noise in different places and provide data to the municipality to take suitable measures for reducing it and reaching an acceptable level [30]. In addition 
to building a space-time map of noise pollution in the area, public security can be provided by mean of sound detectors like glass crashing. This service provides both quiet at night and confidence to public establishment owners [15].

\subsection{Surveillance Systems}

Security is the most significant element of the smart cities from the citizens' point of view. To this end, the entire smart city has to be constantly monitored and observed, but evaluating the information and discovering criminal acts are highly challenging. Reference [1] offered new scenarios to boost smart cities' security. Conventional closed-circuit television (CCTV) systems provide an infrastructure for smart surveillance systems. However they connected to a video recorder; do not have the capability of intelligent processing. Moreover, human operators may miss some scene and cause a fault. With smart surveillance, it is possible to monitor people's actions to find any violent act and even detect the people involved. Smart surveillance systems can alarm in case of any event of interest occurs. It can be used as guidance for the future design of pedestrian facilities or its modification through monitoring people's attitude and finding pedestrian traffic patterns. In a concert or a public place like airports where there are a huge number of people, a crowd control scheme for pedestrian crowd monitoring and emergency management system is necessary. For detection and tracking people at night, infrared cameras are used because they work based on temperature [31]. Another aspect of this system is to detect what kind of objects people are carrying in order to find any illegal or banned object. To this end, video sequence frameworks are applied [32], which work based on considering any irregularities in people's silhouette. This is performed by comparing a template of a normal individual walking in the same direction and in the case of any protrusions and deviation, considered as possible pixels for carrying objects [5]. Some of the other camera surveillance systems can detect abnormal situations include pedestrians crossing the street without crosswalks and vehicles going in a wrong direction by running motion detection algorithms to extract video information and format it in XML, aggregating several frames for performing route detection. Finally, a module classifies reasonable data and translates it to find any abnormalities [33]. This system can be deployed for different targets by simply adapting it to the rules of that certain environment.

\section{IoT Potential Applications for Smart Cities}

Figure 7 demonstrates several possible applications of the IoT for the smart city which are explained in this section.

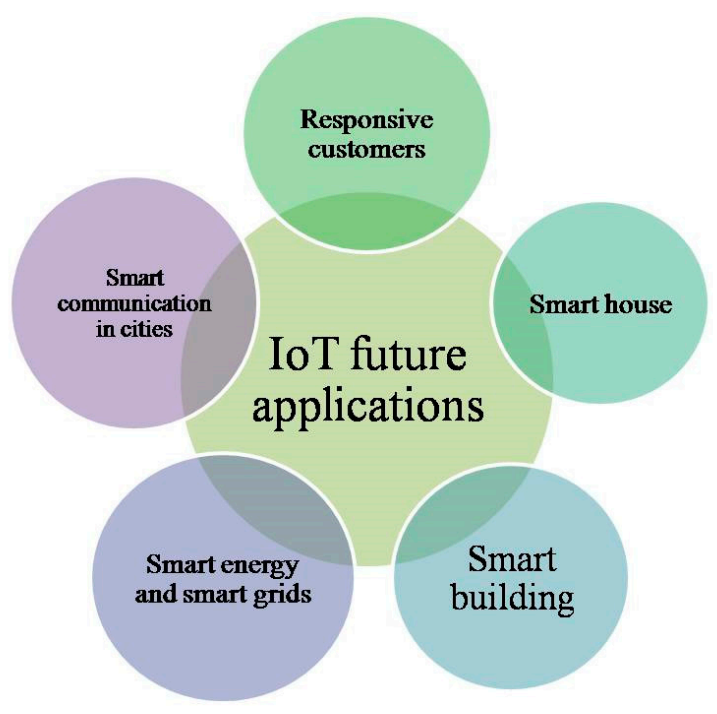

Figure 7. IoT potential for the smart cities. 


\subsection{Smart Cities and Communities}

The successful implementation of the IoT may lead to the production of several services which interact with the environment. Therefore, it can present a number of prospects for contextualization and geo-awareness. Moreover, collective intelligence develops procedures for governing and giving the residents authority and power [34]. Furthermore, a regular middleware can be obtainable for forthcoming services of the smart cities by applying the IoT [35-37]. It is considered that sensor virtualization can be used to reduce the gap between existing technologies and the residents [38].

\subsection{Smart Homes and Buildings}

Utilizing the IoT platform in the houses and buildings, heterogeneous equipment empowers the automation of similar and regular activities. Indeed, through transforming things into appliances' data which are thoroughly linked by applying the Internet can implement services through web interfaces. Sensor networks are utilized by huge numbers of smart home applications. The connection of each smart device to the Internet is realized through the stated applications for monitoring or controlling them distantly [39,40]. For instance, smart lighting has been widely investigated in recent years [41,42]. About $19 \%$ of the total electricity load is used for lighting, which leads to $6 \%$ of the air pollution [43]. Accordingly, about $45 \%$ of the energy needed for lighting can be saved by employing various smart lighting control methods [42]. The main target of smart houses is to reduce the energy consumption in the building because they consume a very large portion of the electricity. Some contributors like heat, ventilation, and air conditioning increase the consumption. Hence, sensing the building to order suitable action is important. Before an action like dimming lights or switching of air conditioning occurs, the environment state is checked, and this is conducted by smart meters. It can aid in demand prediction as well.

\subsection{Responsive Customers}

Transactive controllers and lots of additional smart devices are able to be used to arrange smart households [44-47]. To permit the house controllers to cooperate with aggregators, who are responsible for gathering information from lots of houses, a home gateway is introduced in [44]. According to the signals received from transactive controllers, an aggregation entity can define the electricity purchase price from the grid and send the acceptance/rejection signals of bids to the devices.

The monitoring/controlling ability of each electrical appliance enhances a portion of an active customer in the system operation which is called DR. Demand side activities form a major part of energy policy decisions of the International Energy Agency (IEA), because of the technical and economic benefits $[45,46,48,49]$. In fact, Demand Side Management (DSM) is the modification of consumers' energy consumption curve according to varying electricity price over time and some other payment incentives from utility companies [50]. The main targets of DR are to minimize the consumer's electricity bill, the operation cost of the power grid electricity loss and greenhouse gas emissions and maximize shift peak load demand [45,51]. Based on DR, electricity customers can alter their consumption patterns according to the aim of reliability improvement or avoiding price spikes [52,53]. IoT components collect the electricity requirements of various home appliances and send them to smart meters. The central controller in smart grid schedules energy consumption of homes' appliances according to the user's preferences in a strategy that minimizes the electricity bill and maximizes the security and reliability of the network.

The expectations regarding upcoming electrical systems are mostly focused on the significance of smart grids, renewable energies, emission reduction, and developed DR programs [53]. Smart grids concentrated on the environmentally-based schemes incorporating various renewable resources and DR for providing various choices for customers and improving the utilization of facilities $[24,51,54]$. The DSM problem can be implemented at various levels of the hierarchical smart grid infrastructure. By considering it at the level of home premises, consumers' privacy will be kept [51-55]. Running 
DSM at higher levels, more optimized scheduling plan is generated which both of consumers and utility company take its advantages [56,57]. Electric Vehicles (EVs) are another piece of customer equipment that contributes to demand side management. They are considered as energy storage devices which can provide efficient and clean transportation services. Through efficient scheduling methods for charging and discharging of EVs, the peak load is shaved, emissions are reduced, and the usage of renewable energy sources are increased [58]. To improve the efficiency of charging and discharging scheduling method, sensors collect information about electric vehicles' identity, battery state and location [4].

\subsection{Smart Energy and Smart Grids}

The usage of the IoT allows smart management and control of energy distribution as well as consumption in heterogeneous conditions. The IoT node has various capabilities like sensing and networking that increase the probability of optimum development of energy providers. This management is able to be developed for emergency circumstances. Some significant outcomes of the mentioned development are fault location, isolating as well as service restoration [59]. Accomplishment this feature because of the IoT may provide a progressive tool that defines the location of the faulty sections, isolates them and conducts switching actions to recover the healthy section. Likewise, at the advanced level, this task is extended by applying self-healing approaches which can activate the contribution of the consumers and distributed generators [60]. Applying these methods will lead to reliability improvement, power quality enhancement and profit growth [60].

\section{Practical Experience around the World}

According to the US National Intelligence Council present, the IoT is one of the most efficient sources of US economic profits on the way to 2025 [11]. As declared earlier, the interlinked objects were more than the people in 2011. This tendency has been increasing remarkably as the number of interlinked objects was around nine billion in 2012, whereas it is expected to be 24 billion till 2020 [8]. Accordingly, the IoT is going to be a significant resource for big data in the future [38]. The major strategies, rules, and results of a smart city have been reported by the Intelligent Community Forum awards from 1999 to 2010, for the following cities. Suwon and Seoul (South Korea), Taipei (Taiwan), Mitaka (Japan), Singapore, Waterloo and Calgary (Canada), Glasgow (Scotland), New York City and Georgia (USA), and Tehran (Iran) which have been appreciated for their efforts, and attainment in organizing broadband networks and e-services to support progressive eco-systems [61-68]. There are some examples around the world which show the development of enhanced experiences in individuals, organizations, and society.

\subsection{Amsterdam, The Netherlands}

A number of projects were launched in 2006 in Amsterdam, The Netherlands, including connected public lighting within the smart city. Artificial lighting plays a vital role in cities not only for the dark period of time but also for the prestige of the city which determines the city's degree of ability to invite others there for business or tourism. Therefore, LED lighting was applied with smart controllers for reducing the consumption, which can generate energy savings of up to 80 percent and savings of about 130 billion euro, while providing a greater sense of safety for citizens and more visibility. Moreover, these systems have been interconnected by incorporating controls via the Internet which leads to more energy savings. As a result, instead of physical failure inspection as in traditional lighting operations, the lighting failures are automatically reported by remote monitoring in a novel method. Plus, energy consumption was roughly estimated earlier, but now smart meters accurately calculate the energy consumption. Moreover, lights are dimmed during low traffic hours to save energy or enhanced when needed to improve the safety [69]. 


\subsection{Chicago and New York, USA}

In Chicago City and Chicago's South Side neighborhoods, using digital tools including the web, mobile, and SMS, communities such as residents, organizations, police and public communities try to share information and overcome violent crime. In this project which is supported by the University of Chicago, by spreading the trust among neighbors and local organizations, a general conversation about the crime is created. To this end, a different source of data collected by police, users, and agencies will be available for a smart-phone application that uses a simple mapping interface and GPS [69].

In New York, a platform called City24/7 has been created to inform, protect and revitalize the city. To this end, public communication became more accessible anytime, anywhere on any devices in such a way that the platform integrates information from open government programs, local citizens and business to provide awareness. Therefore, this program delivers the information that people need to know. Some smart screens are in bus stops, train stations, shopping malls and sport facilities to get these data. This can be accessed via Wi-Fi on nearby smartphones or laptops. These smart screens inform people with information that is relevant to their immediate proximity, protect them by giving local police and fire department citywide sensing and communication capabilities. With the growth of smart screens all over the city, the amount of data grows and delivers more value to cities, businesses and citizens [69].

\subsection{Busan, South Korea}

In Busan, South Korea, the government recognized the potential for providing job opportunities for university graduate and economic growth through using ICT. Busan has a good communication infrastructure which enabled the government to expand the cloud infrastructure [70]. It connects universities, industries, citizens and government for driving sustainable urban development. Nowadays, the cloud connects the Busan government, Busan Mobile Application Center (BMAC) and universities. BMAC suggests a physical workspace like project and meeting rooms, shared application development, cloud platforms for Windows or Mac OS devices, consulting centers for start-ups, small/home-office professionals, application library, testing tools, an application programming interface for access to municipal data which provides convenient access to municipal data from the city's geographic information and intelligent transportation systems. It can help to improve city operation, quality of life and citizens' access to services. Since then, a huge number of apps or application development ideas has been received; some new businesses registered as start-ups and many individuals registered as professional application developers. As a result, developers through a shared platform can work with the city to create smart city services [69].

\subsection{Nice, France}

In Nice, France, the potential for implementation of the internet of energy (IoE) was investigated, and the IP-enabled technology architecture, economic model and social benefits of IoE were tested and validated. Then four smart city services were established including smart lighting, smart circulation, smart waste management and smart environment monitoring. According to this project, they found it is possible to apply logged data across different services. For example, data captured by sensors for traffic patterns can serve for smart parking and environmental monitoring [69].

\subsection{Padova, Italy}

In Padova, Italy, the University of Padova, in collaboration with the municipality of the city, started a project called Padova Smart City, which is an obvious example of private and public cooperation for running a smart city. The municipality as a financial sponsor provides the required infrastructure and budget and the university as a theoretical party implements the smart city concept. According to this project, various kinds of sensors are placed on street light poles and connected to the Internet through gateways for collecting environmental and public street lighting data by means of wireless nodes. 
Environmental parameters such as $\mathrm{CO}$ level, air temperature and humidity, vibrations, noise, and so on are collected, while providing a simple but accurate mechanism to check the correct operation of the public lighting system by measuring the light intensity. Although this pilot project is simple, it includes a number of devices and layer technologies that are representative of most of the critical issues which should be taken care of it for design an urban IoT [15]. Table 1 classifies the practical experiences of some smart cities all over the world.

Table 1. The outcomes of cities related to the smart city.

\begin{tabular}{cl}
\hline City & Outcomes \\
\hline Amsterdam [61] & Traffic-reduction, energy conservation, and improvement of the security level \\
\hline Barcelona [62-66] & $\begin{array}{l}\text { Accomplishment of sensor technologies, utilizing the information evaluation of traffic } \\
\text { flows to design new bus networks as well as the accomplishment of smart traffic }\end{array}$ \\
\hline Stockholm [67] & Providing global fiber optic networks all over Stockholm \\
\hline Santa Cruz [68] & $\begin{array}{l}\text { Analyzing the information of criminal actions to predict the requirements of police } \\
\text { and to find the maximum presence of police in the needed regions }\end{array}$ \\
\hline Songdo, Korea [70] & Fully automated buildings, smart street lighting, smart meters and telepresence \\
\hline PlanIT Valley, Portugal [5] & Deployment of 100,000,000 sensors \\
\hline Fujisawa, Japan [5] & Decrease carbon footprint by 70\% \\
\hline Groening, & $\begin{array}{l}\text { Improvement of public transportation systems with real-time access to locationss and } \\
\text { schedules }\end{array}$ \\
\hline The Netherlands [5] & $\begin{array}{l}\text { Improvement of data delivery services, data collection and system analysis for the } \\
\text { municipality }\end{array}$ \\
\hline Norfolk, England [5] & Smart parking systems \\
\hline Vienna, Austria [5] & Increasing energy efficiency and climate protection, reduction in carbon footprint \\
\hline
\end{tabular}

\subsection{Business Models and Scaling-Up Practical Smart Grids}

The smart grids business model can be classified into three classes, including web-based, network ownership and e-commerce, which can have three business models involving open, free and unbundling. However smart grids are provided based on getting special values such as money to a network provider, internal efficiency in a web-based model, and city attractiveness to e-commerce models, that are not obtained when projects move to the business model. Some of the current business models for smart cities are as follows:

1- Temper: The value is creating business opportunities, the business model is open network and the pattern is open.

2- Geneva: The value is developing high-speed networks and smart grids for energy management, the business model is open access and the pattern is open.

3- Seoul: The value is creating a city as a product, the business model is a full-service provider, and the pattern is unbundling.

4- London: The value is managing climate change, the business model is the full-service provider, and the pattern is unbundling [71].

Although many smart grid pilot projects have been developed through either national and public funding or private investment especially over Europe, significant concern has been raised by funders, policy makers and investors about the effect of these pilot projects because most of them have not scaled up after the funding and subsidies dried up without achieving a remarkable impact. Based on the type of investor, the aims of conducting a smart city project can be different. Discovering customer behavior toward new technologies, showing the applicability of technologies on a small scale to commercialize in the future and achieving sustainability goals are some of the smart grid projects participants' objectives. Most of these pilot projects do not focus on the upscaling while starting up, 
therefore, after ending the pilot project, there is no certain program for upscaling. Nevertheless, lack of upscaling for smart grid projects cannot be considered an unsuccessful outcome if the implementation results of a pilot project generate lessons useful for upcoming projects [72]. This lesson can just be the effect of new instruments or to get experience from the implementation of a project in a small building block to see its effects. Moreover, the smart cities and their interconnection in all terms can be very safe through implementing blockchains in the IoT. The blockchain enables smart cities to have a distributed peer-to-peer network where non-trusting members are connected. In fact, the blockchain-IoT combination is a powerful method to make a smart city applicable and provide a new business model in order to keep the privacy between members [73].

\section{Challenges}

This section presents the current challenges for the implementation of IoT-based smart cities. Different IoT challenges for smart grids are demonstrated in Figure 8 and the expression of each one is as follows:

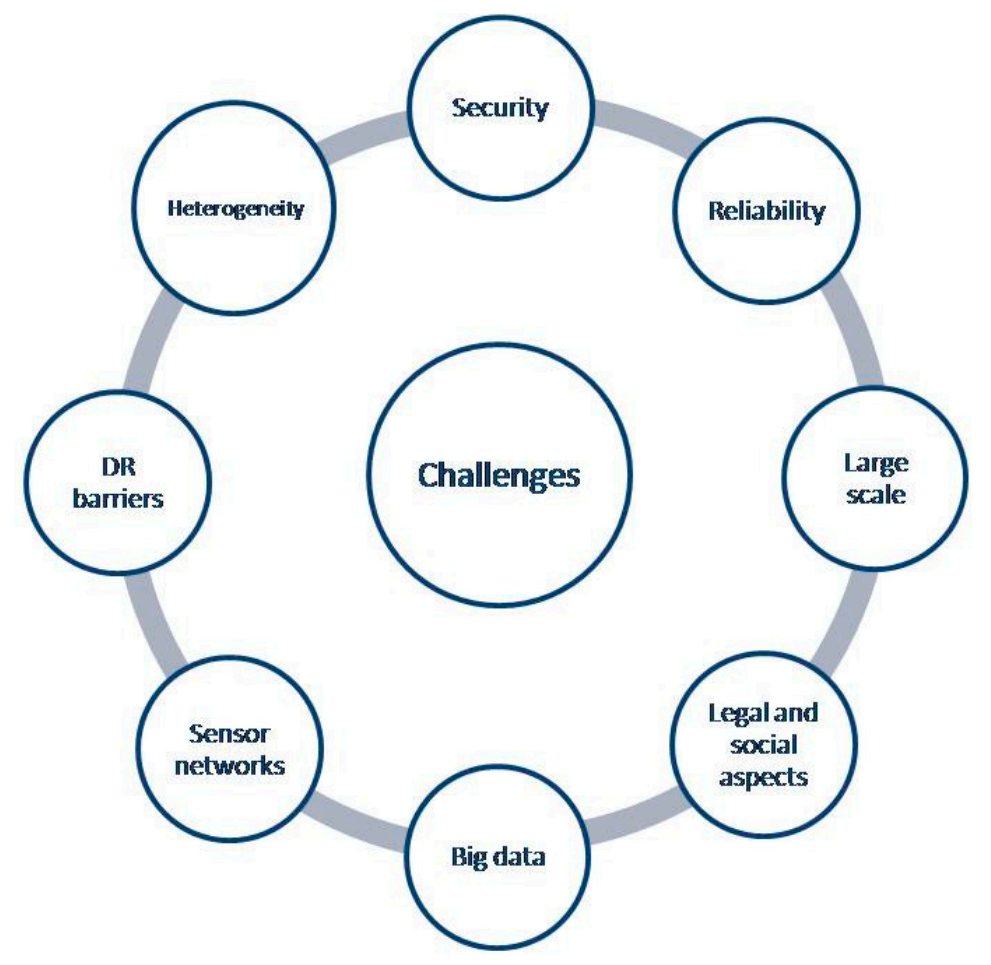

Figure 8. IoT challenges for smart cities.

\subsection{Security and Privacy}

When all the information is gathered and evaluated in the same IoT platform, the system may confront numerous attacks such as cross-site scripting, and side-channels. Moreover, the system can be subjected to significant vulnerabilities. In addition, its multi-tenancy may lead to the security problems as well and result in data leakage [3]. Therefore, cities must adopt serious measures to ensure the privacy and security of citizen data. Without this guarantee, citizens cannot trust to government, and the colection of the information will be difficult. All systems should be resistant against cyber-attacks, particularly the critical infrastructure like smart meters. As a result, for successful implementation of IoT, cities should place privacy and security as a top priority. In Figure 9, some aspects of security in IoT including privacy, trust and data confidentiality as well as their solutions are presented. 


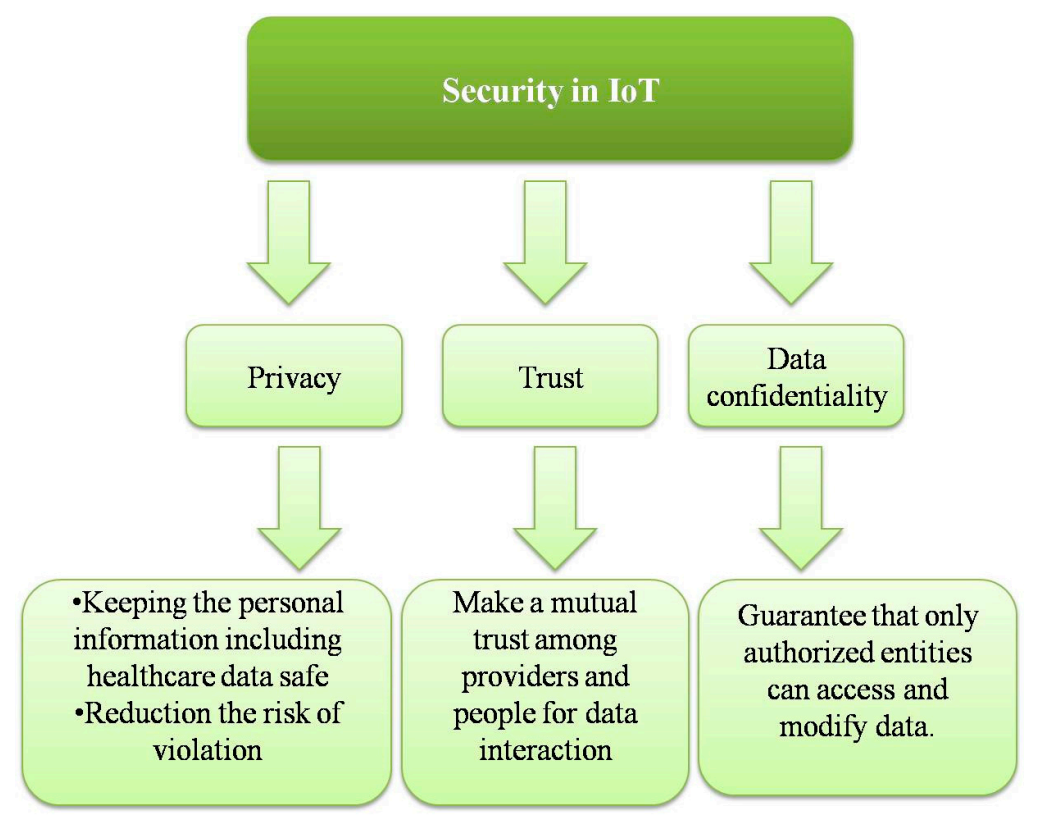

Figure 9. Security aspects in IoT.

\subsection{Heterogeneity}

IoT systems have usually developed with specific and notable solutions in which each element of the system is joined to the special application context. On this basis, the authorities have to examine their goal scenarios, define the needed hardware/software and afterward aggregate these heterogeneous subsystems. Providing such substructures and the procurement of a proper cooperating scheme among them is indeed a major challenging mission for IoT systems.

\subsection{Reliability}

IoT-based systems cause some reliability problems. For example, due to cars' mobility, the interconnection among them is not very reliable. Moreover, the participation of huge numbers of smart technologies would lead to some reliability challenges, particularly regarding their failure [74].

\subsection{Large Scale}

A number of defined scenarios need interactions among the enormous amount of distributed devices that are likely to be embedded in a wide area environment. The IoT system provides a proper platform which is able to analyze and aggregate information extracted from various devices $[3,67,68,74-78]$. However, this large-scale data needs proper storage and computational ability because it is gathered at high rates that lead to the usual challenges to be more difficult to cope with. In addition, the distribution of the IoT devices can influence the monitoring actions, since the devices have to deal with delays related to dynamics and connectivity.

\subsection{Legal and Social Aspects}

The IoT system likely is a service according to the user-provided data. For such terms, the service providers have to be based on various local and international rules. Likewise, the applicants are faced with sufficient incentives to attend a specified scenario and data gathering. It would be more comfortable if the opportunity were given to the applicants to choose and participate in the registration information that indicates an event [78]. Reference [79] handled the subject of systems that include people as a source of data to provide safe interactions. 


\subsection{Big Data}

Considering around 50,000,000,000 devices, it is definitely essential to pay attention to data transfer, storage and recall as well as analyze the large amount of information generated by them [3]. It is clear that the IoT substructures would be some of these significant sources of big data. In big data problems, three main specifications are highlighted, consisting of the number, speed as well as variance. Hence, smart meter information is received according to these specifications.

\subsection{Sensor Networks}

Sensor networks can be taken into account as a remarkable technology for enabling the IoT [80]. They can form the world by providing the capabilities of measuring, inferring, and understanding environmental indexes [8]. Current development and improvement in technologies have provided efficient and cheap devices for applying to large-scale remote sensing utilizations [81]. Moreover, smartphones contain various kinds of sensors and, as a result, they empower different kinds of mobile usages in different areas of the IoT. For this purpose, the main challenging action can be how to process the large-scale information of the sensors regarding energy and network constraints and different types of uncertainty [82].

\subsection{DR Barriers}

The IoT is able to assist the contribution of the responsive demand in the system. There are still different barriers which can restrict participation in DR programs. As illustrated in Figure 10, these barriers can be categorized into three key sets, namely customer' barriers, providers' barriers, and framework barriers which are comprehensively studied in [83].

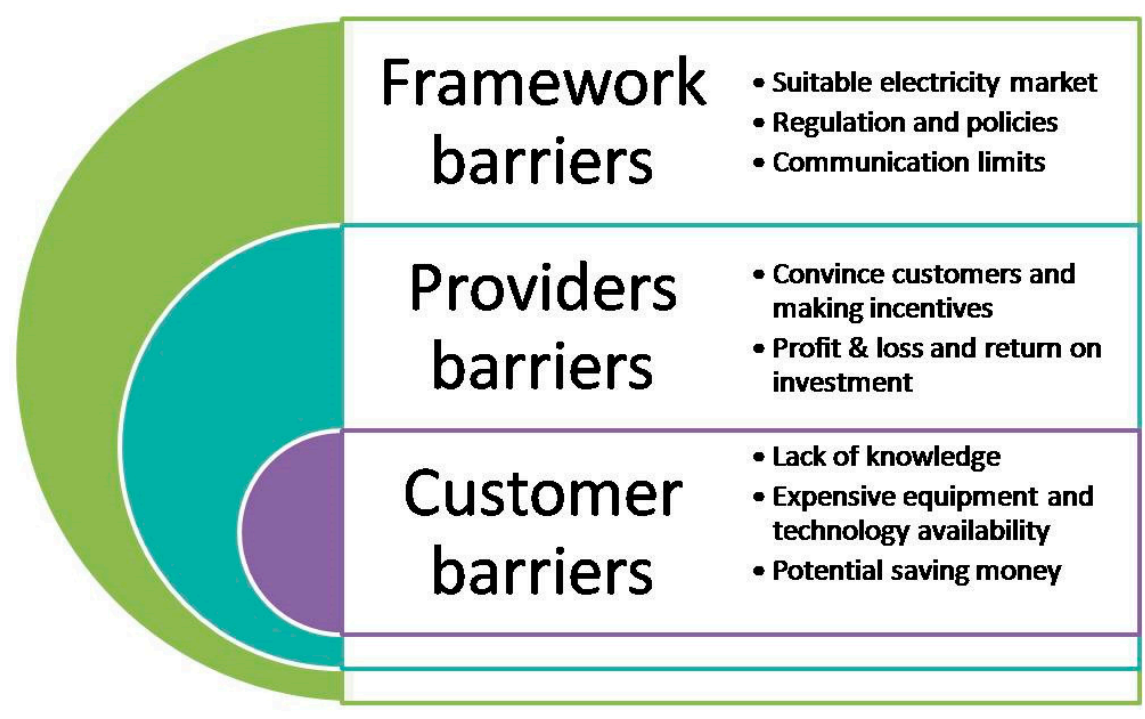

Figure 10. DR barriers.

\section{Conclusions, Remarks and Future Trends}

The importance of considering how new concepts and technologies (especially the IoT) benefit smart cities is undeniable. The aim of this review article was to explore variant specifications and features of IoT systems, along with the efficient incentives for utilizing them. Because the accomplishment of the IoT substructures can enable a volume of opportunities for smart cities, first, the most important research motivations were expressed and afterward, several main and helpful applications explained. It was illustrated how daily activities could be extended and improved through employing them. Likewise, the challenges arising from implementing the IoT system were accordingly outlined. On this subject, the incorporation of the IoT platform into other independent and smart 
systems to provide an intelligent and widespread utilization is one of the most interesting future tendencies. Moreover, providing a methodology to cope with some important challenges, such as the privacy rights of the users/residents, is still an area of research interest. Some of the developments in the actual implementation of smart cities across the world were presented, which can be considered as samples or pilot projects for future comprehensive smart cities. The IoT through its functionality and specifications should indeed employ smart systems and sensors to ensure residents' rights.

Acknowledgments: João P. S. Catalão acknowledges the support by FEDER funds through COMPETE 2020 and by Portuguese funds through FCT, under Projects SAICT-PAC/0004/2015-POCI-01-0145-FEDER-016434, POCI-01-0145-FEDER-006961, UID/EEA/50014/2013, UID/CEC/50021/2013, and UID/EMS/00151/2013, and also funding from the EU 7th Framework Programme FP7/2007-2013 under GA No. 309048.

Author Contributions: All authors have worked on this manuscript together and all authors have read and approved the final manuscript.

Conflicts of Interest: The authors declare no conflict of interest.

\section{References}

1. Rathore, M.M.; Ahmad, A.; Paul, A.; Rho, S. Urban planning and building smart cities based on the Internet of Things using Big Data analytics. Comput. Netw. 2016, 101, 63-80. [CrossRef]

2. Zhu, C.; Leung, V.C.M.; Shu, L.; Ngai, E.C.H. Green Internet of Things for Smart World. IEEE Access 2015, 3, 2151-2162. [CrossRef]

3. Botta, A.; de Donato, W.; Persico, V.; Pescapé, A. Integration of Cloud computing and Internet of Things: A survey. Future Gener. Comput. Syst. 2016, 56, 684-700. [CrossRef]

4. Jaradat, M.; Jarrah, M.; Bousselham, A.; Jararweh, Y.; Al-Ayyoub, M. The Internet of Energy: Smart Sensor Networks and Big Data Management for Smart Grid. Procedia Comput. Sci. 2015, 56, 592-597. [CrossRef]

5. Hancke, G.; Silva, B.; Hancke, G., Jr. The Role of Advanced Sensing in Smart Cities. Sensors 2012, 13, 393-425. [CrossRef] [PubMed]

6. Kyriazis, D.; Varvarigou, T.; White, D.; Rossi, A.; Cooper, J. Sustainable smart city IoT applications: Heat and electricity management amp; Eco-conscious cruise control for public transportation. In Proceedings of the 2013 IEEE 14th International Symposium on "A World of Wireless, Mobile and Multimedia Networks" (WoWMoM), Madrid, Spain, 4-7 June 2013; pp. 1-5.

7. Strategic Opportunity Analysis of the Global Smart City Market. Available online: http://www.egr.msu. edu/ aesc310-web/resources/SmartCities/Smart\%20City\%20Market\%20Report\%202.pdf (accessed on 24 February 2017).

8. Gubbi, J.; Buyya, R.; Marusic, S.; Palaniswami, M. Internet of Things (IoT): A vision, architectural elements, and future directions. Future Gener. Comput. Syst. 2013, 29, 1645-1660. [CrossRef]

9. Atzori, L.; Iera, A.; Morabito, G. The Internet of Things: A survey. Comput. Netw. 2010, 54, 2787-2805. [CrossRef]

10. Internet of Things in 2020: Roadmap for the Future. Available online: http://www.smart-systemsintegration.org/public/documents/publications/Internet-of-Things_in_2020_EC-EPoSS_Workshop_ Report_2008_v3.pdf (accessed on 24 February 2017).

11. Six Technologies with Potential Impacts on US Interests Out to 2025. Available online: https://fas.org/irp/ nic/disruptive.pdf (accessed on 24 February 2017).

12. Alamri, A.; Ansari, W.S.; Hassan, M.M.; Hossain, M.S.; Alelaiwi, A.; Hossain, M.A. A Survey on Sensor-Cloud: Architecture, Applications, and Approaches. Int. J. Distrib. Sens. Netw. 2013, 9, 917923. [CrossRef]

13. Kosmatos, E.A.; Tselikas, N.D.; Boucouvalas, A.C. Integrating RFIDs and Smart Objects into a UnifiedInternet of Things Architecture. Adv. Internet Things 2011, 1, 5. [CrossRef]

14. Rawat, P.; Singh, K.D.; Chaouchi, H.; Bonnin, J.M. Wireless sensor networks: A survey on recent developments and potential synergies. J. Supercomput. 2014, 68, 1-48. [CrossRef]

15. Zanella, A.; Bui, N.; Castellani, A.; Vangelista, L.; Zorzi, M. Internet of Things for Smart Cities. IEEE Internet Things J. 2014, 1, 22-32. 
16. Medagliani, P.; Leguay, J.; Duda, A.; Rousseau, F.; Duquennoy, S.; Raza, S.; Ferrari, G.; Gonizzi, P.; Cirani, S.; Veltri, L.; et al. Internet of Things Applications-From Research and Innovation to Market Deployment. In Bringing IP to Low-Power Smart Objects: The Smart Parking Case in the CALIPSO Project; The River Publisher Series in Communication: Delft, The Netherlands, 2014; pp. 287-313.

17. Elmangoush, A.; Alhazmi, A.; Magedanz, T.; Schuch, W.; Estevez, C.; Ehijo, A.; Wu, J.; Nguyen, T.; Ventura, N.; Mwangama, J.; et al. Towards Unified Smart City Communication Platforms. In Proceedings of the Workshop on Research in Information Systems and Technologies, Chillán, Chile, 16 October 2015.

18. IEEE-SA-IEEE Get 802 Program-802.15: Wireless PANs. Available online: https://standards.ieee.org/ about/get/802/802.15.html (accessed on 24 February 2017).

19. Shafie-Khah, M.; Heydarian-Forushani, E.; Osório, G.J.; Gil, F.A.S.; Aghaei, J.; Barani, M.; Catalão, J.P.S. Optimal Behavior of Electric Vehicle Parking Lots as Demand Response Aggregation Agents. IEEE Trans. Smart Grid 2016, 7, 2654-2665. [CrossRef]

20. Li, X.; Lu, R.; Liang, X.; Shen, X.; Chen, J.; Lin, X. Smart community: An internet of things application. IEEE Commun. Mag. 2011, 49, 68-75. [CrossRef]

21. Stratigea, A. The concept of "smart cities". Towards community development? Netcom. Réseaux Commun. Territ. 2012, 26-3/4, 375-388. [CrossRef]

22. Neyestani, N.; Damavandi, M.Y.; Shafie-khah, M.; Catalão, J.P.S. Modeling the PEV traffic pattern in an urban environment with parking lots and charging stations. In Proceedings of the 2015 IEEE Eindhoven PowerTech, Eindhoven, The Netherlands, 29 June-2 July 2015; pp. 1-6.

23. Yazdani-Damavandi, M.; Moghaddam, M.P.; Haghifam, M.R.; Shafie-khah, M.; Catalão, J.P.S. Modeling Operational Behavior of Plug-in Electric Vehicles' Parking Lot in Multienergy Systems. IEEE Trans. Smart Grid 2016, 7, 124-135. [CrossRef]

24. Neyestani, N.; Damavandi, M.Y.; Shafie-Khah, M.; Contreras, J.; Catalão, J.P.S. Allocation of Plug-In Vehicles' Parking Lots in Distribution Systems Considering Network-Constrained Objectives. IEEE Trans. Power Syst. 2015, 30, 2643-2656. [CrossRef]

25. Lee, S.; Yoon, D.; Ghosh, A. Intelligent parking lot application using wireless sensor networks. In Proceedings of the 2008 International Symposium on Collaborative Technologies and Systems, Irvine, CA, USA, 19-23 May 2008; pp. 48-57.

26. Niyato, D.; Hossain, E.; Camorlinga, S. Remote patient monitoring service using heterogeneous wireless access networks: Architecture and optimization. IEEE J. Sel. Areas Commun. 2009, 27, 412-423. [CrossRef]

27. The Urban Internet of Things. Available online: http:/ / datasmart.ash.harvard.edu/news/article/the-urbaninternet-of-things-727 (accessed on 24 February 2017).

28. Shafie-Khah, M.; Heydarian-Forushani, E.; Golshan, M.E.H.; Siano, P.; Moghaddam, M.P.; Sheikh-El-Eslami, M.K.; Catalão, J.P.S. Optimal trading of plug-in electric vehicle aggregation agents in a market environment for sustainability. Appl. Energy 2016, 162, 601-612. [CrossRef]

29. Li, X.; Shu, W.; Li, M.; Huang, H.Y.; Luo, P.E.; Wu, M.Y. Performance Evaluation of Vehicle-Based Mobile Sensor Networks for Traffic Monitoring. IEEE Trans. Veh. Technol. 2009, 58, 1647-1653.

30. Maisonneuve, N.; Stevens, M.; Niessen, M.E.; Hanappe, P.; Steels, L. Citizen Noise Pollution Monitoring. In Proceedings of the 10th Annual International Conference on Digital Government Research: Social Networks: Making Connections between Citizens, Data and Government, Puebla, Mexico, 17-21 May 2009; pp. 96-103.

31. Wang, J.; Chen, D.; Chen, H.; Yang, J. On pedestrian detection and tracking in infrared videos. Pattern Recognit. Lett. 2012, 33, 775-785. [CrossRef]

32. Damen, D.; Hogg, D. Detecting Carried Objects from Sequences of Walking Pedestrians. IEEE Trans. Pattern Anal. Mach. Intell. 2012, 34, 1056-1067. [CrossRef] [PubMed]

33. Calavia, L.; Baladrón, C.; Aguiar, J.M.; Carro, B.; Sánchez-Esguevillas, A. A semantic autonomous video surveillance system for dense camera networks in Smart Cities. Sensors 2012, 12, 10407-10429. [CrossRef] [PubMed]

34. Leadership in Enabling and Industrial Technologies-Horizon 2020_European Commission. Available online: http:/ / programmes/horizon2020/en/h2020-section/leadership-enabling-and-industrial-technologies (accessed on 24 February 2017). 
35. Ballon, P.; Glidden, J.; Kranas, P.; Menychtas, A.; Ruston, S.; van der Graaf, S. Is there a need for a Cloud platform for European smart cities? In Proceedings of the eChallenges 2011 Conference and Exhibition, Florence, Italy, 26-28 October 2011; International Information Management Corporation: Dublin, Ireland, 2011.

36. Suciu, G.; Vulpe, A.; Halunga, S.; Fratu, O.; Todoran, G.; Suciu, V. Smart Cities Built on Resilient Cloud Computing and Secure Internet of Things. In Proceedings of the 2013 19th International Conference on Control Systems and Computer Science, Bucharest, Romania, 29-31 May 2013; pp. 513-518.

37. ClouT I ClouT: Cloud of Things for Empowering the Citizen Clout in Smart Cities. Available online: http:/ / clout-project.eu/ (accessed on 24 February 2017).

38. Petrolo, R.; Mitton, N.; Soldatos, J.; Hauswirth, M.; Schiele, G. Integrating wireless sensor networks within a city cloud. In Proceedings of the 2014 Eleventh Annual IEEE International Conference on Sensing, Communication, and Networking Workshops (SECON Workshops), Singapore, 30 June-3 July 2014; pp. 24-27.

39. Chen, S.Y.; Lai, C.F.; Huang, Y.M.; Jeng, Y.L. Intelligent home-appliance recognition over IoT cloud network. In Proceedings of the 2013 9th International Wireless Communications and Mobile Computing Conference (IWCMC), Sardinia, Italy, 1-5 July 2013; pp. 639-643.

40. Han, D.M.; Lim, J.H. Smart home energy management system using IEEE 802.15.4 and zigbee. IEEE Trans. Consum. Electron. 2010, 56, 1403-1410. [CrossRef]

41. Ye, X.; Huang, J. A framework for Cloud-based Smart Home. In Proceedings of the 2011 International Conference on Computer Science and Network Technology, Harbin, China, 24-26 December 2011; Volume 2, pp. 894-897.

42. Martirano, L. A smart lighting control to save energy. In Proceedings of the 6th IEEE International Conference on Intelligent Data Acquisition and Advanced Computing Systems, Prague, Czech Republic, 15-17 September 2011; Volume 1, pp. 132-138.

43. Castro, M.; Jara, A.J.; Skarmeta, A.F.G. Smart Lighting Solutions for Smart Cities. In Proceedings of the 2013 27th International Conference on Advanced Information Networking and Applications Workshops, Barcelona, Spain, 25-28 March 2013; pp. 1374-1379.

44. Siano, P.; Sarno, D. Assessing the benefits of residential demand response in a real time distribution energy market. Appl. Energy 2016, 161, 533-551. [CrossRef]

45. Siano, P. Demand response and smart grids-A survey. Renew. Sustain. Energy Rev. 2014, 30, 461-478. [CrossRef]

46. Graditi, G.; Ippolito, M.G.; Lamedica, R.; Piccolo, A.; Ruvio, A.; Santini, E.; Siano, P.; Zizzo, G. Innovative control logics for a rational utilization of electric loads and air-conditioning systems in a residential building. Energy Build. 2015, 102, 1-17.

47. Siano, P.; Graditi, G.; Atrigna, M.; Piccolo, A. Designing and testing decision support and energy management systems for smart homes. J. Ambient Intell. Human. Comput. 2013, 4, 651-661. [CrossRef]

48. Strategic Plan for the IEA Demand-Side Management Programme 2008-2012. Available online: http:/ / www. ieadsm.org/wp/files/Exco\%20File\%20Library/Participation/Final\%20strategy\%202008-2012.pdf (accessed on 24 February 2017).

49. Arasteh, H.R.; Parsa Moghaddam, M.; Sheikh-El-Eslami, M.K.; Abdollahi, A. Integrating commercial demand response resources with unit commitment. Int. J. Electr. Power Energy Syst. 2013, 51, 153-161. [CrossRef]

50. Balijepalli, V.S.K.M.; Pradhan, V.; Khaparde, S.A.; Shereef, R.M. Review of demand response under smart grid paradigm. In Proceedings of the ISGT2011-India, Kerala, India, 1-3 December 2011; pp. 236-243.

51. Koutsopoulos, I.; Tassiulas, L. Control and Optimization Meet the Smart Power Grid-Scheduling of Power Demands for Optimal Energy Management. In Proceedings of the 2nd International Conference on Energy-Efficient Computing and Networking, New York, NY, USA, 31 May-1 June 2011.

52. Parvania, M.; Fotuhi-Firuzabad, M. Demand Response Scheduling by Stochastic SCUC. IEEE Trans. Smart Grid 2010, 1, 89-98. [CrossRef]

53. Electricity Technology Roadmap: Meeting the Critical Challenges of the 21st Century—Roadmap2003. Available online: http:/ /mydocs.epri.com/docs/CorporateDocuments/StrategicVision/Roadmap2003.pdf (accessed on 24 February 2017).

54. Arritt, R.F.; Dugan, R.C. Distribution System Analysis and the Future Smart Grid. IEEE Trans. Ind. Appl. 2011, 47, 2343-2350. [CrossRef] 
55. Jaradat, M.; Jarrah, M.; Jararweh, Y.; Al-Ayyoub, M.; Bousselham, A. Integration of renewable energy in demand-side management for home appliances. In Proceedings of the 2014 International Renewable and Sustainable Energy Conference (IRSEC), Ouarzazate, Morocco, 17-19 October 2014; pp. 571-576.

56. Zhu, Z.; Tang, J.; Lambotharan, S.; Chin, W.H.; Fan, Z. An integer linear programming based optimization for home demand-side management in smart grid. In Proceedings of the 2012 IEEE PES Innovative Smart Grid Technologies (ISGT), Washington, DC, USA, 16-20 January 2012; pp. 1-5.

57. Nguyen, H.K.; Song, J.B.; Han, Z. Demand side management to reduce Peak-to-Average Ratio using game theory in smart grid. In Proceedings of the 2012 Proceedings IEEE INFOCOM Workshops, Orlando, FL, USA, 25-30 March 2012; pp. 91-96.

58. Saber, A.Y.; Venayagamoorthy, G.K. Plug-in Vehicles and Renewable Energy Sources for Cost and Emission Reductions. IEEE Trans. Ind. Electron. 2011, 58, 1229-1238.

59. Zhabelova, G.; Vyatkin, V. Multiagent Smart Grid Automation Architecture Based on IEC 61850/61499 Intelligent Logical Nodes. IEEE Trans. Ind. Electron. 2012, 59, 2351-2362. [CrossRef]

60. Miao, Y.; Bu, Y. Research on the architecture and key technology of Internet of Things (IoT) applied on smart grid. In Proceedings of the 2010 International Conference on Advances in Energy Engineering (ICAEE), Beijing, China, 19-20 June 2010; pp. 69-72.

61. Amsterdam Smart City. Available online: https://amsterdamsmartcity.com/ (accessed on 24 February 2017).

62. Smart City | Servei de Premsa I El Web de la Ciutat de Barcelona. Available online: http://ajuntament. barcelona.cat/premsa/tag/smart-city/ (accessed on 24 February 2017).

63. Laursen, L. City Saves Money, Attracts Businesses with Smart City Strategy. Available online: https://www. technologyreview.com/s/532511/barcelonas-smart-city-ecosystem/ (accessed on 24 February 2017).

64. TMBAPP (Metro Bus Barcelona) I Apps I iTunes I apps4BCN I All the Apps You Need for Barcelona! Available online: http://apps4bcn.cat/en/app/tmbapp-metro-bus-barcelona/111 (accessed on 24 February 2017).

65. Transport \& Traffic | IOS | The Best App Selection for Barcelona | Apps4bcn | All the Apps You Need for Barcelona! Available online: http://apps4bcn.cat/en/apps/index/Category:transport-i-tr-nsit (accessed on 24 February 2017).

66. UrbanStep Barcelona | Apps I iTunes I apps4BCN | All the Apps You Need for Barcelona! Available online: http://apps4bcn.cat/en/app/urbanstep-barcelona/110 (accessed on 24 February 2017).

67. ICT Regulation Toolkit. Available online: http://www.ictregulationtoolkit.org/practice_note?practice_note_ id=3244 (accessed on 24 February 2017).

68. Writer, S.B.-S. Staff Modest Gains in First Six Months of Santa Cruz's Predictive Police Program. Available online: http:/ /www.santacruzsentinel.com/article/zz/20120226/NEWS/120227300 (accessed on 24 February 2017).

69. The Internet of Everything for Cities. Available online: http://pie.pascalobservatory.org/sites/default/ files/ioe-smart-city_pov.pdf (accessed on 24 February 2017).

70. Strickland, E. Cisco bets on South Korean smart city. IEEE Spectr. 2011, 48, 11-12. [CrossRef]

71. Anthopoulos, L.G.; Fitsilis, P. Understanding Smart City Business Models: A Comparison; ACM Press: New York, NY, USA, 2015; pp. 529-534.

72. Smart City Pilot Projects, Scaling Up or Fading Out? Experiences from Amsterdam. Available online: http://www.hva.nl/urban-management/over-um/nieuws/content/nieuwsberichten/2016/3/ willem-van-winden-discussion.html (accessed on 24 February 2017).

73. Christidis, K.; Devetsikiotis, M. Blockchains and Smart Contracts for the Internet of Things. IEEE Access 2016, 4, 2292-2303. [CrossRef]

74. He, W.; Yan, G.; Xu, L.D. Developing Vehicular Data Cloud Services in the IoT Environment. IEEE Trans. Ind. Inform. 2014, 10, 1587-1595. [CrossRef]

75. Petrolo, R.; Loscrì, V.; Mitton, N. Towards a smart city based on cloud of things, a survey on the smart city vision and paradigms. Trans. Emerg. Telecommun. Technol. 2017, 28, e2931. [CrossRef]

76. Lazarescu, M.T. Design of a WSN Platform for Long-Term Environmental Monitoring for IoT Applications. IEEE J. Emerg. Sel. Top. Circuits Syst. 2013, 3, 45-54. [CrossRef]

77. Mitton, N.; Papavassiliou, S.; Puliafito, A.; Trivedi, K.S. Combining Cloud and sensors in a smart city environment. EURASIP J. Wirel. Commun. Netw. 2012, 2012, 247. [CrossRef] 
78. Atkins, C.; Koyanagi, K.; Tsuchiya, T.; Miyosawa, T.; Hirose, H.; Sawano, H. A Cloud Service for End-User Participation Concerning the Internet of Things. In Proceedings of the 2013 International Conference on Signal-Image Technology Internet-Based Systems, Kyoto, Japan, 2-5 December 2013; pp. 273-278.

79. Corsar, D.; Edwards, P.; Velaga, N.; Nelson, J.; Pan, J. Short Paper: Addressing the Challenges of Semantic Citizen-sensing. In Proceedings of the 4th International Conference on Semantic Sensor Networks, SSN'11, Aachen, Germany, 23 October 2011; Volume 839, pp. 101-106.

80. Zaslavsky, A.; Perera, C.; Georgakopoulos, D. Sensing as a Service and Big Data. In Proceedings of the International Conference on Advances in Cloud Computing (ACC), Bangalore, India, July 2012.

81. Akyildiz, I.F.; Melodia, T.; Chowdury, K.R. Wireless multimedia sensor networks: A survey. IEEE Wirel. Commun. 2007, 14, 32-39. [CrossRef]

82. Zhao, F. Sensors meet the Cloud: Planetary-scale distributed sensing and decision making. In Proceedings of the 2010 9th IEEE International Conference on Cognitive Informatics (ICCI), Beijing, China, 7-9 July 2010; pp. 998-998.

83. Kim, J.-H.; Shcherbakova, A. Common failures of demand response. Energy 2011, 36, 873-880. [CrossRef]

(C) 2017 by the authors. Licensee MDPI, Basel, Switzerland. This article is an open access article distributed under the terms and conditions of the Creative Commons Attribution (CC BY) license (http:// creativecommons.org/licenses/by/4.0/). 